\title{
Nanocomposites based on plasma-polymerized carbon nanotubes and Nylon-6
}

\author{
Víctor J Cruz-Delgado ${ }^{1}$, Beatriz L España-Sánchez ${ }^{1}$, Carlos A Avila-Orta ${ }^{1}$ and Francisco J Medellín-Rodríguez ${ }^{2}$ \\ Unique properties of carbon nanotubes (CNTs) and Nylon-6 were combined to obtain nanocomposites through in situ \\ polymerization. For this purpose, plasma-polymerized CNTs (CNTM) and raw CNTs were added to in situ polymerization of \\ €-caprolactam and 6-aminocapropic acid to obtain nanocomposites with 2 and $4 \% \mathrm{wt} / \mathrm{wt}$ of nanotubes. The morphology, \\ phase transitions, thermal stability, dispersion and electrical conductivity were investigated for all samples. Scanning electron \\ microscopy images showed a homogeneous dispersion of CNTs; however, dispersion is known to be better in nanocomposites \\ with CNTM. Furthermore, the crystallization temperature increased up to $50{ }^{\circ} \mathrm{C}$, the melting temperature increased by $20^{\circ} \mathrm{C}$ and \\ the degradation temperature increased up to $70^{\circ} \mathrm{C}$ for a $10 \%$ weight loss. This behavior suggests a synergistic effect for these \\ nanocomposites. The electrical conductivity of nanocomposites with $4 \% \mathrm{wt} / \mathrm{wt}$ reached a maximum of $10^{-4} \mathrm{Scm}^{-1}$, suggesting \\ a semiconductive material. Finally, the method used in this work is effective for the dispersion of CNTs, and it can be used to \\ form nanocomposites with improved properties compared with the Nylon-6 homopolymer.
}

Polymer Journal (2012) 44, 952-958; doi:10.1038/pj.2012.49; published online 25 April 2012

Keywords: nanocomposites; Nylon; plasma polymerization; thermal properties

\section{INTRODUCTION}

Carbon nanotubes (CNTs) have been employed to reinforce semicrystalline polymers, leading to a new class of material called polymer nanocomposites. ${ }^{1}$ The use of CNTs in polymer matrices promotes an increase in mechanical properties, such as Young's modulus, tensile strength and storage modulus. ${ }^{2}$ Different methods to obtain fully exfoliated nanoparticles in polymer nanocomposites have been used. The first one was attributed to Usuki et al. ${ }^{3}$ of Toyota Central Research \& Development, who successfully prepared an exfoliated Nylon-6/montmorillonite hybrid, via in situ polymerization of $\epsilon$-caprolactam, in which alkylammonium-modified montmorillonite was thoroughly dispersed, called Nylon-6 clay hybrid. Recently, Li et al. ${ }^{4}$ reported that under controlled conditions, CNTs can be periodically decorated with semicrystalline polymers during crystallization in solution. The periodically decorated CNTs were called nanohybrid shish-kebabs. The possible formation mechanism is under investigation, but it is believed that electrostatic charges could be responsible for creating nanohybrid shish-kebabs. In contrast, Gao et al. ${ }^{1}$ reported a chemical processing technology to obtain nanohybrids that involves the in situ polymerization of $\epsilon$-caprolactam in the presence of single-walled carbon nanotubes (SWCNTs). This process implies a chemical condensation reaction between functionalized CNTs with carboxylic groups and $\epsilon$-caprolactam during interfacial polymerization of Nylon-6. Tensile tests of the obtained fibers were improved by functional groups grafted to the CNTs. These authors reported a possible chemical pathway to form a nanohybrid during the synthesis of SWCNT-Nylon composites.

Separation at the individual level of nanoparticles is one of the most challenging issues in polymer nanocomposites to obtain a reinforcing effect, strong nucleating effect, enhanced thermal stability and electrical conductivity. To overcome this requirement, several procedures have been conducted to modify the surface properties of carbon nanoparticles (functionalization) to reach a high dispersion level or exfoliation into polymers., ${ }^{2,5}$ Among others, surface modification by plasma polymerization has gained particular attention as a promising technology for surface modification of nanoparticles. ${ }^{7}$ It is worth mentioning that plasma polymerization is a fast, dry and environmentally friendly process.

Shi et al. ${ }^{8}$ conducted one of the pioneering works in the field of nanoparticle surface modification. These authors describe the plasma polymerization of styrene over carbon nanofibers (CNFs) and its incorporation into polystyrene (PS) by solution mixing. Tensile tests for the nanocomposites showed an increase up to $25 \%$ for a concentration of $3 \% \mathrm{wt} / \mathrm{wt}$ of modified CNFs. Meanwhile, for nanocomposites with unmodified CNFs, the mechanical properties are lower than those of the pure polystyrene (PS). The authors noted that the surface modification enhances the dispersion and interfacial adhesion with the polymer matrix and is responsible for the

${ }^{1}$ Departamento de Materiales Avanzados, Centro de Investigación en Química Aplicada, Saltillo, México and ${ }^{2}$ CIEP/FCQ, Universidad Autónoma de San Luis Potosí. Av. Manuel Nava 6, Zona Universitaria, San Luis Potosí, México

Correspondence: Dr CA Avila-Orta, Departamento de Materiales Avanzados, Centro de Investigación en Química Aplicada, Boulevard Enrique Reyna \# 140, Saltillo 25253, Mexico. E-mail: cavila@ciqa.mx.

Received 17 October 2011; revised 24 January 2012; accepted 21 February 2012; published online 25 April 2012 
increase in mechanical properties. A similar strategy was adopted for Ramos-de Valle et al. ${ }^{9}$ to produce nanocomposites of PS (polystyrene)/CNF by melt mixing. With the incorporation of modified CNFs in concentrations of 3 and $5 \% \mathrm{wt} / \mathrm{wt}$, the tensile modulus was increased by $100 \%$ and $130 \%$, respectively. Electron microscopy of the tensile specimens revealed the strongest interfacial adhesion between the modified CNFs and the polymer host, while at the same time showing a homogeneous dispersion in the whole matrix.

In another study, the surface of multiwalled carbon nanotubes (MWCNTs) was modified with a methyl methacrylate plasma and incorporated into polymethyl methacrylate by means of melt mixing. ${ }^{5}$ The conformal polymer coating had a significant effect on the mechanical properties at a $1 \% \mathrm{wt} / \mathrm{wt}$ concentration of modified MWCNTs compared with the uncoated MWCNTs. Nevertheless, this increase was marginal with respect to pure polymethyl methacrylate.

In contrast, polyethylene terephthalate (PET) was melt-mixed with MWCNTs modified by an ethylene glycol plasma. ${ }^{10}$ Morphological characterization of the nanocomposites by a theoretical analysis (Ozawa's analysis) suggested that MWCNTs confine the growth of polymer crystallites and reduce the normal $3 \mathrm{D}$ geometry to $2 \mathrm{D}$ by the presence of CNTs. The increase in crystallization temperatures and reduction in crystallization time supported the idea of MWCNTs having a nucleating effect, as was evidenced by the mean of the thermal analysis. The electrical conductivities of nanocomposites with $2 \% \mathrm{wt} / \mathrm{wt}$ of MWCNTs reach values of 2.48 and $2.78 \times 10^{-4} \mathrm{~S} \mathrm{~cm}^{-1}$ for unmodified and modified MWCNTs, respectively, which suggests that plasma polymerization does not reduce the conductive ability of CNTs. Moreover, it has been demonstrated that the outer walls of CNTs can be covered by an ultrathin coating of cross-linked polymers with functional groups. ${ }^{11}$

Recently, Hernandez-Hernandez et al. ${ }^{12}$ reported the surface modification of CNFs with an acrylic acid plasma and the incorporation of Nylon- 6 in a thermoplastic matrix by melt mixing in a concentration of $3 \% \mathrm{wt} / \mathrm{wt}$. Electron microscopy revealed the dispersion and high compatibility between CNFs and the Nylon-6 matrix; the tensile toughness and tensile modulus were enhanced by 52 and $88 \%$, respectively, in comparison with pure Nylon-6. A thermal analysis evidenced the nucleation activity of CNF by increasing the crystallization temperature. The crystal structure was evaluated by X-ray dispersion. The presence of the $\alpha$-phase of Nylon- 6 in all of the nanocomposites suggests formation of the most stable crystalline phase induced by CNFs.

In this work, surface modification of CNTs with acrylic acid plasma was carried out so that the modified CNTs (CNTM) could be incorporated during in situ polymerization of Nylon-6 to obtain nanocomposites and assess the influence of surface modification on the morphology, thermal transitions, crystal structure, dispersion and electrical properties of nanocomposites obtained with 2 and $4 \% \mathrm{wt} / \mathrm{wt}$ of CNTs and CNTMs.

\section{EXPERIMENTAL PROCEDURE}

\section{Materials}

MWCNTs were purchased from NanoLab Inc., Waltham, MA, USA. A chemical vapor deposition process was used to obtain the nanotubes, which have an average outer diameter of $30 \mathrm{~nm}$, lengths of $1-5 \mu \mathrm{m}$ and $95 \%$ purity. Acrylic acid, reagent grade (Sigma-Aldrich, St Louis, MO, USA) was distilled before plasma polymerization. $\epsilon$-caprolactam (UNIVEX, Monterrey, Nuevo León, Mexico) and 6-aminocaproic acid (Sigma-Aldrich) were both reagent grade and used as received for the polymerization of Nylon-6.

\section{Methodology}

Surface modification of CNTs with acrylic acid plasma. The surface of CNTs was chemically modified with $\mathrm{COOH}$ groups using plasma polymerization of acrylic acid. For this purpose, a radiofrequency plasma reactor of $13.56 \mathrm{MHz}$ with an output power of $50 \mathrm{~W}$ was used. The treatment time was $30 \mathrm{~min}$, with a pressure of $0.2 \mathrm{mbar}$. The monomer of acrylic acid was contained in a Schlenck tube and fed to the system through a needle valve with a flow rate of $0.15 \mathrm{~cm}^{3}$ per min. The system was shaken to improve homogeneous modification, as described in a previous paper. ${ }^{11}$ Samples modified with the plasma treatment will be denoted as CNTM, and unmodified samples will be denoted as CNTs.

In situ polymerization. A method reported by Usuki et al. ${ }^{3}$ to prepare hybrid nanocomposites by in situ polymerization of Nylon-6 in the presence of nanoclays was used to prepare Nylon-6/CNT and Nylon-6/CNTM nanocomposites. A 250-ml Parr reactor (series 4576) with a controlled temperature, pressure and stirring speed was used for Nylon-6 preparation. A ratio of $6.7 / 1$ of $\epsilon$-caprolactam monomer to 6-aminocaproic acid catalysts was used for all Nylon- 6 polymerizations. In the case of nanocomposites, 2 and $4 \% \mathrm{wt} / \mathrm{wt}$ of CNTs or CNTM were used. The reactants were poured into the reactor, which was then sealed; a vacuum was created slowly over a period of $5 \mathrm{~min}$, and the reactor volume was then saturated with high-purity $\mathrm{N}_{2}$ gas. This procedure was repeated three times to ensure an inert atmosphere. The reaction system was heated up to $100^{\circ} \mathrm{C}$ and stirred at 600 r.p.m. for $30 \mathrm{~min}$. Then, the temperature was increased slowly up to $260^{\circ} \mathrm{C}$, and the system was kept at this temperature for $6 \mathrm{~h}$, stirring intermittently every $15 \mathrm{~min}$. A pressure of 21 psig was maintained during the whole process. The solid product was washed with water at $80^{\circ} \mathrm{C}$ for $1 \mathrm{~h}$ and dried using a vacuum oven at $70{ }^{\circ} \mathrm{C}$ for $48 \mathrm{~h}$. The resulting Nylon-6 and nanocomposites were molded into a stainlesssteel mold using a Mettler Hot Stage FP82HT (Mettler, Columbus, OH, USA). The samples were first melted at $260^{\circ} \mathrm{C}$ for $3 \mathrm{~min}$ and then cooled down to room temperature at a cooling rate of $10^{\circ} \mathrm{C}$ per min.

\section{Characterization}

Fourier-Transform Infra Red (FTIR) was used to determine the presence of $\mathrm{COOH}$ groups for nanotube samples before and after the surface modification. A Nicolet (Waltham, MA, USA, Magna 550) spectrometer was used, with a resolution of $4 \mathrm{~cm}^{-1}$ and 30 scans per sample. The samples were analyzed using a $\mathrm{KBr}$ disk.

A TITAN- $300 \mathrm{kV}$ field emission gun microscope (Titan, Eindhoven, The Netherlands), which has a symmetrical condenser-objective lens type S-TWIN $(\mathrm{Cs}=1.3 \mathrm{~mm})$ was used to analyze the morphology of the CNT and CNTM samples. The high-resolution transmission electron microscopy images have been registered in a CCD camera near the Scherzer focus.

The thermal behavior of all samples during non-isothermal crystallization and melting was obtained using a TA Instruments differential scanning calorimeter model 2920 . The samples were heated up to $260^{\circ} \mathrm{C}$ and kept at this temperature for $3 \mathrm{~min}$ before cooling them down to room temperature (non-isothermal crystallization) and then heating them up again to $260^{\circ} \mathrm{C}$ (melting). The cooling/heating rate was $10^{\circ} \mathrm{C}$ per min, and the nitrogen flow rate was $50 \mathrm{ml}$ per min.

The crystalline form of Nylon- 6 and nanocomposites was investigated using a Siemens XRD model D5000 X-ray diffractometer (Siemens, Madison, WI, USA). A voltage of $20 \mathrm{kV}$ and a current intensity of $25 \mathrm{~mA}$ were used. Nonisothermally crystallized samples were scanned within the range of $5^{\circ}$ to $35^{\circ}$ of the $2 \theta$ angle. The scanning rate was $0.03^{\circ}$ per min.

To observe the dispersion of the nanotubes into Nylon-6, a FE-SEM (field emission scanning electron microscope) JEOL model JSM-7401 F (JEOL, Peabody, MA, USA) was used. Non-isothermally crystallized molded samples were cryogenically fractured and coated with $\mathrm{Au} / \mathrm{Pd}$. The working distance was $3 \mathrm{~mm}$, and $\times 50000$ magnification was employed.

The two-point electrical resistance of non-isothermally crystallized molded samples was determined using a Keithley Source Meter model 2400 (Keithley, Cleveland, OH, USA). An average value was reported after making four measurements. The electrical resistance was then converted to a volume electrical resistivity, and finally to a volume electrical conductivity. 
The thermal stability/degradation of the Nylon-6 and nanocomposites was evaluated using a TA Instruments TGA (thermogravimetric analyzer) model Q500 (TA Instruments, New Castle, DE, USA). The samples were heated from room temperature to $800^{\circ} \mathrm{C}$ with a heating rate of $10^{\circ} \mathrm{C}$ per min and a nitrogen flow rate of $50 \mathrm{ml}$ per min. A total of $10 \mathrm{mg}$ of sample was used for the analysis.

\section{RESULTS AND DISCUSSION}

\section{Surface modification of CNTs}

The compatibility between Nylon- 6 and CNTs can be improved when nanotube surfaces are modified with acid groups. The use of an acrylic acid plasma can produce $\mathrm{COOH}$ groups, as suggested by Hernandez-Hernandez et al, ${ }^{12}$ along with a cross-linked thin polymer film coating. Furthermore, Shi et al. ${ }^{8}$ and Gorga et al. ${ }^{5}$ have reported that this type of surface modification does not compromise the structural integrity of the nanotubes. Ros et al. ${ }^{13}$ studied the surface chemical modification of CNFs by oxidation with acids in which carboxylic groups are preferentially formed, showing an FourierTransform Infra Red (FTIR) signal at $1720 \mathrm{~cm}^{-1}$. Nevertheless, these authors also noted the possible formation of other functional groups, such as carboxylic anhydride groups, lactones, phenols, quinones or ethers, on the surface of CNFs.

To demonstrate the presence of $\mathrm{COOH}$ functional groups on the surface of the CNTs, the nanotubes were analyzed by FourierTransform Infra Red (FTIR) before and after chemical modification, and the results are shown in Figure 1. The signal at $1735 \mathrm{~cm}^{-1}$ (indicated with an arrow), can be associated with the stretch of the $\mathrm{C}=\mathrm{O}$ bond present in carboxylic acids. It can be observed that this signal is present in both the samples. Nevertheless, in raw CNTs, the intensity is lower, which indicates that carboxylic groups are often present. However, they are weakly attached to the raw nanotube surface, while after chemical modification with a plasma treatment they are strongly attached to the nanotube surface. ${ }^{11}$ We consider only the presence of $\mathrm{COOH}$ groups attached to the surface of the CNTs under the experimental conditions used in this study. These $\mathrm{COOH}$ groups are capable of reacting with $\epsilon$-caprolactam and 6-aminocaproic acid during in situ polymerization of Nylon-6, in which a nanohybrid with enhanced properties can be formed. ${ }^{14}$ In contrast, the thin film of plasma-polymerized acrylic acid exhibits two other characteristic signals, $\mathrm{C}=\mathrm{C}$ and $\mathrm{C}-\mathrm{O}$, which are located at 1570 and $1080 \mathrm{~cm}^{-1}$, respectively. They are assigned to the $\mathrm{C}=\mathrm{C}$ double bonds located near the functionalization sites. The signal at $1080 \mathrm{~cm}^{-1}$ could be assigned to the stretching of the $\mathrm{C}-\mathrm{O}$ bond in carboxylic acid, and the signal at $1630 \mathrm{~cm}^{-1}$ corresponds to the $\mathrm{KBr}$ disk, as discussed by Hernandez-Hernandez et al. ${ }^{12}$

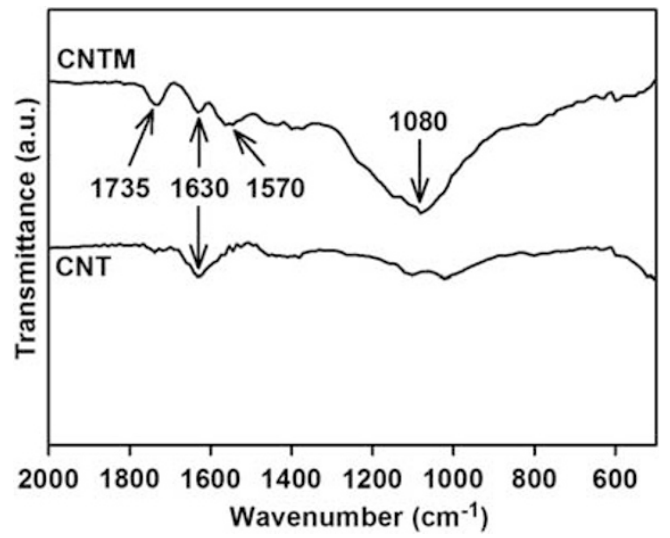

Figure 1 Fourier-Transform Infra Red (FTIR) spectra for carbon nanotubes (CNTS) before (CNT) and after (CNTM) chemical treatment with an acrylic acid plasma.

\section{Morphology by high-resolution transmission electron microscopy} Figure 2 shows high-resolution transmission electron micrographs of CNTs and CNTM. A cross-section of a nanotube comprising several well-defined layers is shown in Figure 2a. Moreover, small deposits of amorphous carbon can be observed (indicated with arrows). In contrast, in CNTM, the presence of an ultrathin coating reveals the surface modification after the plasma polymerization of acrylic acid, generating a coating with a thickness of $2 \mathrm{~nm}$ (Figure 2b), which is similar in size to coatings described in previous papers. ${ }^{7,8,11}$

\section{Non-isothermal crystallization}

Once Nylon-6 and nanocomposites were formed by in situ polymerization, it was desirable to characterize them under the same experimental conditions to establish comparisons. In the first term, we analyzed the differential scanning calorimeter traces of Nylon-6 and nanocomposites during cooling to determine the effect of CNTs on the crystallization behavior. For this purpose, all samples were melted at $260^{\circ} \mathrm{C}$ for $3 \mathrm{~min}$ and then cooled down to room temperature at a fixed rate of $10^{\circ} \mathrm{C}$ per min. The results are shown in Figure 3. In the case of the neat polymer, one exothermic peak was observed. The onset temperature was $165^{\circ} \mathrm{C}$, while the peak temperature was $154^{\circ} \mathrm{C}$. This behavior corresponded well with the crystallization of low-molecular-weight Nylon-6. Nevertheless, two exothermic peaks were present for all nanocomposites at higher temperatures compared with the neat polymer. The exothermic peaks were labeled from right to left. The crystallization onset temperature of exotherm I for the nanocomposites was ca. $212{ }^{\circ} \mathrm{C}$ and encompassed peak temperatures ranging from $207^{\circ} \mathrm{C}$ to $205^{\circ} \mathrm{C}$. In contrast, the peak temperature for exotherm II ranged between $190^{\circ} \mathrm{C}$ and $194^{\circ} \mathrm{C}$. In general, it was observed that the presence of CNTs, either raw or chemically modified, considerably increased the crystallization temperature of Nylon- 6 . The average increase for $T_{\mathrm{c}, \mathrm{I}}$ was approximately $50{ }^{\circ} \mathrm{C}$ and for $T_{\mathrm{c}, \mathrm{II}}$ is $40^{\circ} \mathrm{C}$.

The increase in the crystallization temperature during non-isothermal crystallization from the melt is a clear indication of the strong nucleating effect of CNTs on polymer crystallization. At higher crystallization temperatures, there is a greater nucleating effect. Several studies have been performed in the recent past on the nucleating effect of CNTs in Nylon-6. For example, Sandler et al. ${ }^{15}$ showed an increase in the crystallization temperature of less than $10{ }^{\circ} \mathrm{C}$ when $\mathrm{CNF}$ s were incorporated into the polymer, while no significant change was obtained in the case of CNTs. In another study, Phang et al. ${ }^{16}$ observed an increase of $20^{\circ} \mathrm{C}$ in $T_{\mathrm{c}}$ for nanocomposites with up to $2 \% \mathrm{wt} / \mathrm{wt}$ of MWCNT. Anoop-Anand et al. ${ }^{17}$ observed that the ultrasound-assisted dissolution-evaporation method is effective for disentangling SWCNTs in PET (polyethylene terephthalate)/SWCNT nanocomposites, and they observed an increase of $24{ }^{\circ} \mathrm{C}$ in $T_{\mathrm{c}}$ for nanocomposites with $0.3 \% \mathrm{wt} / \mathrm{wt}$ and of $31{ }^{\circ} \mathrm{C}$ for nanocomposites with $3 \% \mathrm{wt} / \mathrm{wt}$ of SWCNTs. These authors claim that the nucleation efficiency of SWCNTs at low concentrations is due to the good dispersion and the large surface area of the CNTs. In our study, the increase was up to $50{ }^{\circ} \mathrm{C}$, which indicates a homogeneous dispersion and a strong nucleating effect of CNTs onto Nylon-6 and supports the idea of a synergistic effect in nanocomposites.

Two exothermic peaks have been reported previously during nonisothermal crystallization of Nylon- 6 in the presence of MWCNTs. ${ }^{16}$ Nevertheless, the nature of these two peaks has not been discovered. One possibility for the origin of these peaks is that they originate from two different types of crystal structures ( $\alpha$ - or $\gamma$-crystals). Another possibility is step crystallization, and yet another is the existence of 

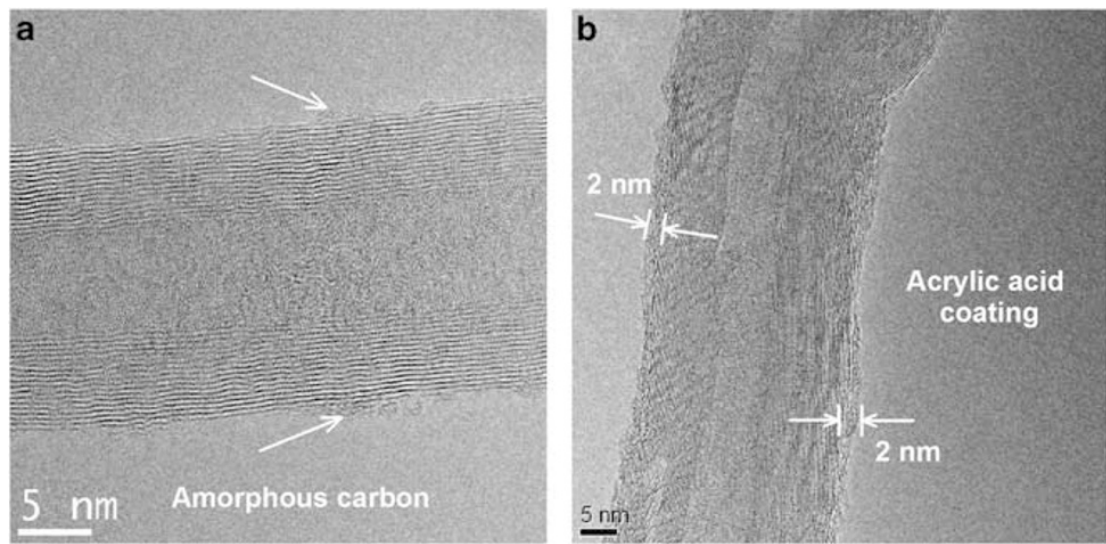

Figure 2 High-resolution transmission electron micrographs for (a) carbon nanotubes (CNTs) and (b) plasma-polymerized CNTs (CNTM).

two different crystalline morphologies. ${ }^{16}$ It is worth mentioning that double crystallization behavior has only been observed when nanocomposites are prepared by in situ polymerization, contrary to the case when they are prepared by melt blending in which only one crystallization peak is observed. ${ }^{15}$

\section{Crystalline structure}

The X-ray diffraction patterns of Nylon- 6 and nanocomposites after non-isothermal crystallization are shown in Figure 4. In general, all samples show two diffraction planes located at $20.66^{\circ}$ and $24.38^{\circ}$ of $2 \theta$, which correspond to the crystallographic planes [200] and [002, $202]$, respectively. These two planes are characteristic of the $\alpha$-form of Nylon-6. ${ }^{18}$ This behavior suggests that the presence of CNTs does not significantly affect the crystalline phase of Nylon-6, at least for the experimental conditions used in this study. The $\alpha$-form is favored, which is the most stable form compared with the $\beta$ - and $\gamma$-forms. ${ }^{19}$ This behavior has been observed in the past by other authors ${ }^{16,20-22}$ who observed no structural change when CNTs are loaded onto Nylon- 6 . The preferred formation of the $\alpha$-form for nanocomposites supports the idea that Nylon- 6 develops a more stable phase in the presence of CNTs, even when high cooling rates are used. ${ }^{23}$

\section{Dispersion}

SEM micrographs of nanocomposites with $4 \% \mathrm{wt} / \mathrm{wt}$ of nanotubes are shown in Figure 5. In Figure 5a, it can be observed that raw CNTs are homogeneously dispersed into Nylon-6, and no agglomeration is present; however, they are slightly entangled. In the case of CNTM, the homogeneous dispersion was enhanced by surface modification, which resulted in CNTs being separated at the individual level and mostly embedded into the matrix (Figure $5 \mathrm{~b}$ ). This suggests that the surface modification has an effective role in producing highly dispersed CNTs that are adhered to the polymer matrix.

The dispersion of CNTs into the Nylon-6 matrix is attributed to the nanocomposite preparation in which $\epsilon$-caprolactam acts as an effective solvent for CNTs and prevents CNT agglomeration during polymerization. Moreover, when the polymeric chain length increases, this will separate the CNTs. In the first stage of polymerization, $\mathrm{COOH}$ functional groups attached to the surface of CNTs react with amine groups of the 6-aminocaproic acid to form the first amide bond, which is part of the global polymerization process, and as the chain grows, this will disentangle the CNTs.

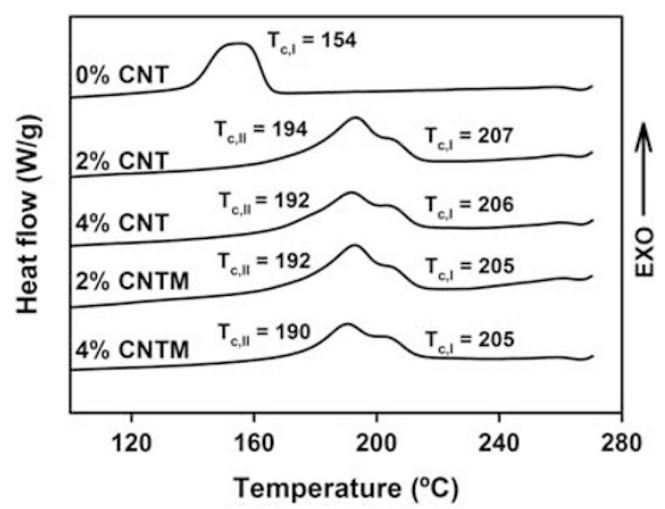

Figure 3 Differential scanning calorimeter traces of Nylon- 6 and nanocomposites during cooling from the melt at a rate of $10^{\circ} \mathrm{C}$ per min.

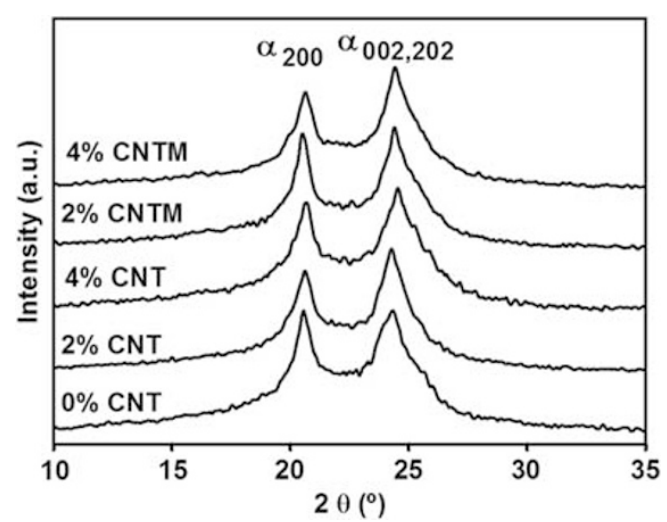

Figure 4 X-ray patterns of Nylon-6 and nanocomposites after non-isothermal crystallization.

Several authors have investigated the dispersion of polymer nanocomposites by electron microscopy. For example, Shi et al. ${ }^{8}$ observed by SEM that chemically functionalized CNFs mixed with polystyrene (PS) adhered to the polymer matrix, but they tended to form agglomerates. Zhang et al. ${ }^{24}$ melt-mixed up to $3 \%$ MWCNTs with Nylon-6 and observed that the nanoparticles were slightly 
adhered to the polymer, but with poor dispersion. Schartel et al. ${ }^{25}$ determined that dilution of a masterbatch of Nylon-6/MWCNT from 20 to $5 \%$ MWCNTs favored nanoparticle dispersion. In summary, it is supposed that homogeneous dispersion of CNTs into a polymer matrix and the adhesion are enhanced with chemical modification of nanoparticles and the nanocomposite preparation method. Hernandez-Hernandez et al. ${ }^{12}$ claim that modification of CNFs by means of plasma polymerization of acrylic acid enhances the dispersion and adhesion of CNFs within the Nylon-6 matrix during melt mixing, as shown in fracture specimens for the tensile test.

\section{Melting behavior}

The melting behavior during controlled heating of non-isothermally crystallized Nylon-6 and nanocomposites is shown in Figure 6. It is readily observed that the melting temperature of the nanocomposites is considerably higher than the one observed for the neat polymer. The increase was up to $20^{\circ} \mathrm{C}$ in the case of CNTM. Interestingly, only one melting peak is observed. Several reports indicated that the melting temperature of the polymer was not affected by the presence of CNFs or CNTs in nanocomposites. ${ }^{12,16,17}$

In contrast, the increase in melting temperature in nanocomposites can be associated with the formation of a more perfect crystal structure compared with the one obtained for the neat polymer. This effect was also observed by Li et al. ${ }^{23}$ in nanocomposites isothermally crystallized at high temperatures, in which the $\alpha$-phase of Nylon- 6 is induced by the presence of MWCNTs.

\section{Thermal stability}

The thermogravimetric analysis of Nylon-6 and nanocomposites is shown in Figure 7. As can be seen, the homopolymer exhibited the lowest thermal stability, while for all nanocomposites a higher thermal stability was observed, which indicates that CNTs can improve their resistance under heating. These results can be related to a homogeneous dispersion of the CNTs in the polymer, as shown in the SEM images. We assume that the degree of dispersion is derived from the agglomerates that break out during the polymerization process. The results in Table 1 can be used to establish a comparison between samples under similar degradation conditions. At the same weight loss percent, that is, at $5 \%$, the thermal stability increased by $50{ }^{\circ} \mathrm{C}$ when carboxylic acids were present on the surface of CNTs; when the weight loss percent was $10 \%$, the thermal stability increased up to $70{ }^{\circ} \mathrm{C}$ compared with the pure Nylon-6. In contrast, when the $50 \%$ degradation temperature $\left(T_{\mathrm{d}, 50 \%}\right)$ was reached, only a minimal enhancement was observed for samples containing $4 \% \mathrm{wt} / \mathrm{wt}$ of
CNTs and CNTM, which is almost $10^{\circ} \mathrm{C}$ higher than the value for the pure Nylon-6, as shown in Table 1.

The thermal stability of Nylon-12/CNF composites with different concentrations was analyzed by Sandler et al. ${ }^{15}$ These authors found that at low CNF concentrations, no apparent change was appreciable, while at concentrations above $15 \% \mathrm{wt} / \mathrm{wt}$, the thermal stability increased dramatically. In contrast, Zeng et al. ${ }^{26}$ studied the thermal stability of Nylon-10-10/MWCNT nanocomposites, for which they observed favorable results at concentrations above $20 \%$. Aguirre-Figueroa ${ }^{27}$ reported the enhancement of thermal stability for

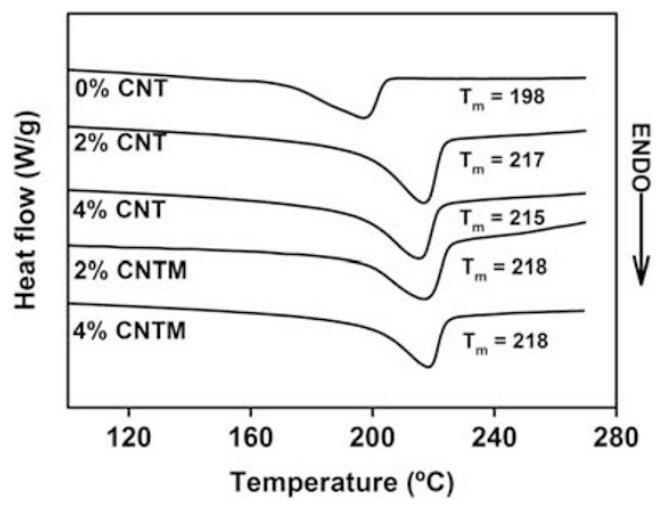

Figure 6 Differential scanning calorimeter traces of Nylon-6 and nanocomposites during heating at a rate of $10^{\circ} \mathrm{C}$ per min. The samples were previously crystallized non-isothermally at a cooling rate of $10^{\circ} \mathrm{C}$ per min.

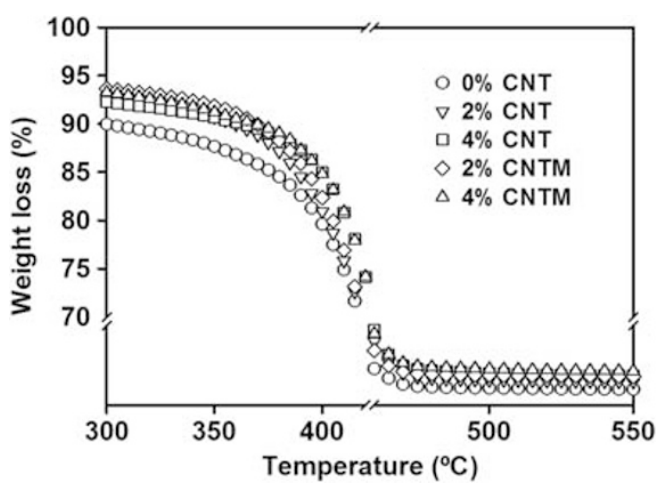

Figure 7 Thermogravimetric analysis plots of Nylon- 6 and nanocomposites during heating at a rate of $10^{\circ} \mathrm{C}$ per min. The samples were previously crystallized non-isothermally at a cooling rate of $10^{\circ} \mathrm{C}$ per min.
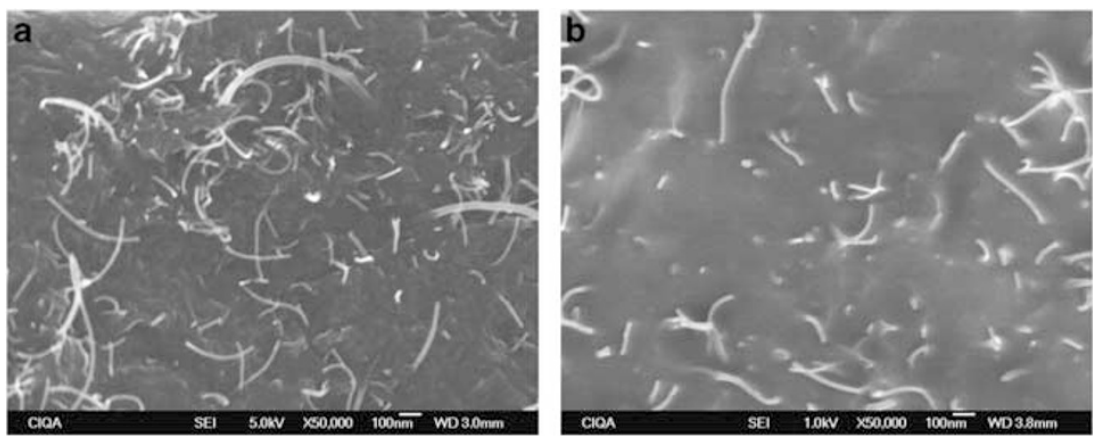

Figure 5 Scanning electron microscope micrographs for nanocomposites (4\% wt/wt carbon nanotubes (CNTs)) after non-isothermal crystallization: (a) Nylon6/CNT and (b) Nylon-6/modified CNTs (CNTM). 
Table 1 Thermal degradation temperature $\left(T_{\mathrm{d}}\right)$ for Nylon- 6 and nanocomposites at different weight percent losses and residues evaluated at $500^{\circ} \mathrm{C}$

\begin{tabular}{lcccc}
\hline Sample & $\mathrm{T}_{d, 5 \%}\left({ }^{\circ} \mathrm{C}\right)$ & $\mathrm{T}_{d, 10 \%}\left({ }^{\circ} \mathrm{C}\right)$ & $\mathrm{T}_{d, 50 \%}\left({ }^{\circ} \mathrm{C}\right)$ & Residue (\%) \\
\hline 0\% CNT & 199 & 299 & 438 & 4.9 \\
$2 \%$ CNT & 226 & 359 & 440 & 6.8 \\
$4 \%$ CNT & 218 & 362 & 444 & 8.6 \\
$2 \%$ CNTM & 250 & 368 & 447 & 6.9 \\
$4 \%$ CNTM & 247 & 369 & 446 & 8.6
\end{tabular}

Abbreviations: CNT, carbon nanotubules; CNTM, plasma-polymerized CNTS (CNTM); Td, thermal degradation temperature.

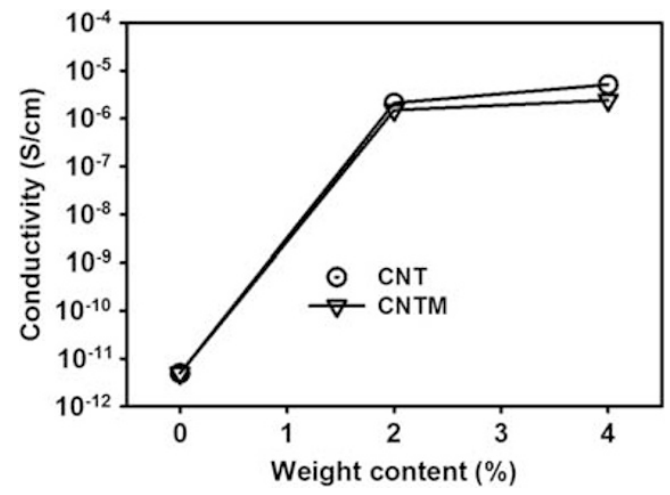

Figure $\mathbf{8}$ Electrical conductivity for Nylon-6 and nanocomposites. The samples were previously crystallized non-isothermally at a cooling rate of $10^{\circ} \mathrm{C}$ per min.

high-molecular-weight polypropylenes at low MWCNTs concentrations, while at low-molecular-weights and low MWCNTs concentrations, no significant improvement was found. All of the above suggests that at low-molecular-weights and low MWCNTs concentrations, no improvement of the thermal stability is expected.

\section{Electrical conductivity}

The electrical conductivities of Nylon- 6 and nanocomposites are shown in Figure 8. Here, it was observed that the electrical conductivity for the neat polymer is on the order of $1 \times 10^{-11} \mathrm{~S}$ per $\mathrm{cm}$. The electrical conductivity increased to $7 \times 10^{-5}$ and $1 \times 10^{-4} \mathrm{~S}$ per $\mathrm{cm}$ for samples containing 2 and $4 \% \mathrm{wt} / \mathrm{wt}$ of CNTs, respectively. This means an increase of up to 7 orders of magnitude compared with the neat polymer. In contrast, for samples containing $2 \%$ and $4 \% \mathrm{wt} / \mathrm{wt}$ of CNTM, the electrical conductivity also increased, but to a lesser extent: $8 \times 10^{-5}$ and $5 \times 10^{-5} \mathrm{~S}$ per $\mathrm{cm}$, respectively. The increase is six orders of magnitude. The difference may arise in the presence of an ultrathin polymer coating on the CNTM samples generated during the plasma modification process, slightly diminishing the electrical conductivity.

Kodgire et al. ${ }^{28}$ reported the melt blending of Nylon- 6 and carbon nanotube composites using MWCNTs and modified MWCNTs. These authors found a linear relationship for the electrical conductivity $(\sigma)$ and the MWCNTs concentration. The values for $\sigma$ were $1 \times 10^{-11}$ and $1 \times 10^{-3} \mathrm{~S}$ per $\mathrm{cm}$ for 2 and $4 \% \mathrm{wt} / \mathrm{wt}$ of MWCNTs, respectively, with a percolation threshold between 2 and 3\% wt/wt. With modified MWCNTs, the values of $\sigma$ obtained were lower, but the percolation shifted towards lower concentrations $(0-0.5 \% \mathrm{wt} / \mathrm{wt})$. These authors suggest that a percolating network is readily formed between modified MWCNTs at low concentrations because they are more homogeneously dispersed than are the raw MWCNTs. Nevertheless, impurities such as catalyst particles in MWCNTs can enhance the electrical response.

\section{CONCLUSIONS}

An improvement in the dispersion of CNTs within a Nylon-6 matrix was attained by an adequate set of conditions during in situ polymerization designed to produce a nanocomposite. The characteristic thermal transitions of these nanocomposites were modified with the addition of 2 and $4 \% \mathrm{wt} / \mathrm{wt}$ of CNTs and CNTM. The crystallization temperature $\left(T_{\mathrm{c}}\right)$ increased up to $50^{\circ} \mathrm{C}$, while the melting temperature $\left(T_{\mathrm{m}}\right)$ increased $20^{\circ} \mathrm{C}$ with respect to neat Nylon- 6 . The crystalline structure and degradation temperature were not significantly affected by raw CNTs or CNTM. SEM images showed homogeneous dispersion for CNTs in nanocomposites, which suggests that the interface between CNTs and Nylon- 6 was improved by plasma surface modification. Moreover, dispersion was enhanced within the organic matrix by the addition of functional groups that can establish a true chemical bond between both organic and inorganic components. The electrical conductivity of the nanocomposites showed an increase up to seven orders of magnitude with respect to neat Nylon-6, suggesting a possible application in electronics. The behavior of nanocomposites suggests a hybrid nature, which could be analyzed in detail in the near future.

\section{ACKNOWLEDGEMENTS}

The supply of $\epsilon$-caprolactam from Carlos Castaños from UNIVEX, Mexico, is appreciated. The support of the National Science and Technology Council of Mexico (CONACyT) under the contract J49551-Y and the granting of a scholarship to Victor J Cruz-Delgado is acknowledged and greatly appreciated. Technical assistance with the material characterization from Guadalupe Mendez, Blanca Huerta and Ma Luisa Lopez is recognized.

1 Gao, J., Zhao, B., Itkis, M., Bekyarova, E., Hu, H., Kranak, V., Yu, A. \& Haddon, R. Chemical engineering of the single-walled carbon nanotube-nylon 6 interface. J. Amer. Chem. Soc. 128, 7492-7496 (2006).

2 Coleman, J., Khan, U., Blau, W. \& Gun'ko, Y. Small but strong: A review of the mechanical properties of carbon nanotube-polymer composites. Carbon 44, 1624-1652 (2006).

3 Usuki, A., Kojima, Y., Kawasumi, M., Okada, A., Fukushima, Y., Kurauchi, T. \& Kamigaito, O. Synthesis of nylon 6-clay hybrid. J. Mater. Res. 8, 1179-1184 (1993).

4 Li, L., Li, B., Hood, M. \& Li, C. Carbon nanotube induced polymer crystallization: the formation of nanohybrid shish-kebabs. Polymer 50, 953-965 (2009).

5 Gorga, R., Lau, K., Gleason, K. \& Cohen, R. The importance of interfacial design at the carbon nanotube/polymer composite interface. J. Appl. Polym. Sci. 102, 1413-1418 (2006).

6 Liu, P. Modifications of carbon nanotubes with polymers. Eur. Polym. J. 41, 2693-2703 (2005).

7 Shi, D., Wang, S., van Ooij, W., Wang, L., Zhao, J. \& Yu, Z. Uniform deposition of ultrathin polymer films on the surfaces of Al[sub 2]O[sub 3] nanoparticles by a plasma treatment. Appl. Phys. Lett. 78, 1243-1245 (2001).

8 Shi, D., Lian, J., He, P., Wang, L., Xiao, F., Yang, L., Schulz, M. \& Mast, D. Plasma coating of carbon nanofibers for enhanced dispersion and interfacial bonding in polymer composites. Appl. Phys. Lett. 83, 5301-5303 (2003).

9 Ramos-de Valle, L., Neira-Velázquez, M. \& Hernández-Hernández, E. Surface modification of CNFs via plasma polymerization of styrene monomer and its effect on the properties of PS/CNF nanocomposites. J. Appl. Polym. Sci 107, 1893-1899 (2008).

10 Cruz-Delgado, V., Esparza-Juárez, M., España-Sánchez, B., Rodríguez-Hernández, M., Avila-Orta, C. \& Medellín-Rodríguez, F. Semiconducting polymer nanocomposites of PET/MWCNT: preparation and characterization. Superficies Vacio 20, 6-11 (2007).

11 Avila-Orta, C., Cruz-Delgado, V., Neira-Velázquez, M., Hernández-Hernández, E., Méndez-Padilla, M. \& Medellín-Rodríguez, F. Surface modification of carbon nanotubes with ethylene glycol plasma. Carbon 47, 1916-1921 (2009).

12 Hernández-Hernández, E., Neira-Velázquez, M., Méndez-Nonell, J. \& Ramos-de Valle L. Surface modification of carbon nanofibers via deposition of an ultrathin coating of plasma-polymerized poly(acrylic acid) and its effect on the properties of polyamide 6/CNF nanocomposites. J. Appl. Polym. Sci. 112, 3510-3518 (2009).

13 Ros, T., van Dillen, A., Geus, J. \& Koningsberger, D. Surface oxidation of carbon nanofibres. Chem. - A Eur. J. 8, 1151-1162 (2002). 
14 Gao, J., Itkis, M., Yu, A., Bekyarova, E., Zhao, B. \& Haddon, R. Continuous spinning of a single-walled carbon nanotube-nylon composite fiber. J. Amer. Chem. Soc. 127, 3847-3854 (2005)

15 Sandler, J., Pegel, S., Cadek, M., Gojny, F., van Es, M., Lohmar, J., Blau, W., Schulte, K. Windle, A. \& Shaffer, M. A comparative study of melt spun polyamide-12 fibres reinforced with carbon nanotubes and nanofibres. Polymer 45, 2001-2015 (2004).

16 Phang, I., Ma, J., Shen, L., Liu, T. \& Zhang, W. Crystallization and melting behavior of multi-walled carbon nanotube-reinforced nylon-6 composites. Polym. Int. 55, 71-79 (2006).

17 Anand, K., Agarwal, U., Nisal, A. \& Joseph, R. PET-SWNT nanocomposites through ultrasound assisted dissolution-evaporation. Eur. Polym. J. 43, 2279-2285 (2007).

18 Murthy, N. \& Minor, H. General procedure for evaluating amorphous scattering and crystallinity from X-ray diffraction scans of semicrystalline polymers. Polymer $\mathbf{3 1}$, 996-1002 (1990).

19 Abu-lsa, I. $\alpha-\gamma$ transition in nylon 6. J. Polym. Sci. Part A-1. 9 199-216 (1971).

20 Bhattacharyya, A., Pötschke, P., Haufbler, L. \& Fischer, D. Reactive compatibilization of melt mixed PA6/SWNT composites: mechanical properties and morphology. Macromol. Chem. Phys. 206, 2084-2095 (2005)

$21 \mathrm{Li}, \mathrm{L} ., \mathrm{Li}, \mathrm{C} ., \mathrm{Ni}, \mathrm{C} ., \mathrm{Rong}, \mathrm{L}$. \& Hsiao, B. Structure and crystallization behavior of Nylon 66/multi-walled carbon nanotube nanocomposites at low carbon nanotube contents. Polymer 48, 3452-3460 (2007).
22 Liu, T., Phang, I., Shen, L., Chow, S. \& Zhang, W. Morphology and mechanical properties of multiwalled carbon nanotubes reinforced Nylon- 6 composites. Macromolecules 37, 7214-7222 (2004).

23 Li, J., Fang, Z., Tong, L., Gu, A. \& Liu, F. Polymorphism of nylon-6 in multiwalled carbon nanotubes/nylon-6 composites. J. Polym. Sci. B: Polym. Phys 44, 1499-1512 (2006).

24 Zhang, W., Shen, L., Phang, I. \& Liu, T. Carbon nanotubes reinforced nylon-6 composite prepared by simple melt-compounding. Macromolecules 37, 256-259 (2004).

25 Schartel, B., Pötschke, P., Knoll, U. \& Abdel-Goad, M. Fire behaviour of polyamide 6/multiwall carbon nanotube nanocomposites. Eur. Polym. J. 41, 1061-1070 (2005).

26 Zeng, H., Gao, C., Wang, Y., Watts, P., Kong, H., Cui, X. \& Yan, D. In situ polymerization approach to multiwalled carbon nanotubes-reinforced nylon 1010 composites: Mechanical properties and crystallization behavior. Polymer 47, 113-122 (2006).

27 Aguirre-Figueroa, Y. Thermal Degradation and Stability of iPP/MWCNT Polyme Nanocomposites: Dispersion Effects. BSc Thesis, Instituto Tecnologico de Saltillo Saltillo, Coahuila. Mexico (2007)

28 Kodgire, P., Bhattacharyya, A., Bose, S., Gupta, N., Kulkarni, A. \& Misra, A. Control of multiwall carbon nanotubes dispersion in polyamide6 matrix: An assessment through electrical conductivity. Chem. Phys. Lett. 432, 480-485 (2006). 